OPEN ACCESS

Edited by:

Kum Fai Yuen,

Nanyang Technological University,

Singapore

Reviewed by:

Marcus Geoffrey Haward,

University of Tasmania, Australia

Florian Grisel,

University of Oxford, United Kingdom

*Correspondence:

Emily Cowan

Emily.cowan@sintef.no

tORCID:

Emily Cowan

orcid.org/0000-0002-3550-0449

Rachel Tiller

orcid.org/0000-0002-2505-9194

Specialty section:

This article was submitted to

Marine Affairs and Policy,

a section of the journal

Frontiers in Marine Science

Received: 20 October 2021 Accepted: 01 November 2021 Published: 30 November 2021

Citation:

Cowan E and Tiller R (2021) What Shall We Do With a Sea of Plastics?

A Systematic Literature Review on How to Pave the Road Toward a Global Comprehensive Plastic

Governance Agreement.

Front. Mar. Sci. 8:798534. doi: 10.3389/fmars.2021.798534

\section{What Shall We Do With a Sea of Plastics? A Systematic Literature Review on How to Pave the Road Toward a Global Comprehensive Plastic Governance Agreement}

\author{
Emily Cowan ${ }^{\star \dagger}$ and Rachel Tillert \\ Department of Climate and Environment, SINTEF Ocean, Trondheim, Norway
}

In February 2022, the United Nations Environmental Assembly (UNEA) is expected to mandate negotiations for a legally binding plastic agreement. In preparations for such discussions, it is important to understand the academic research behind what a global treaty on plastic will require to succeed. Therefore, a systematic literature review was conducted on 64 peer-reviewed articles published before July $4^{\text {th }}, 2021$, that focused on global plastic governance and avenues to mitigate our pollution crisis. Once reviewed, the articles were organized into a series of four main categories: (1) plastic pollution overview articles, (2) top-down solutions, (3) bottom-up solutions, and finally a (4) global treaty as a solution. The analysis of these articles enabled an overarching review and discussion of what the literature suggested is required for the creation of a global plastics agreement. First, the researchers argued that previous global plastics governance literature is characterized by an optimist governance perspective, i.e., a view of governance as a problem-solving mechanism. Second, global plastics governance as a research field could make headway by engaging in further empirical investigation of current negotiations and solutions at the national level, especially in developing nations. In the end we found that a global agreement is feasible if it allows for multi-stakeholder solutions involving industry, governance, stakeholders, and citizens.

Keywords: plastic pollution, extended producer responsibility, global plastic governance, international agreement, literature review

\section{INTRODUCTION}

The research community began publishing studies on plastic and marine litter as early as 1968 and 1975 (Borja and Elliott, 2019). These became regular topics in the literature from 1981 to 1987, respectively, but with a decidedly heavy focus on contamination (waste that enters nature) and pollution (when the contamination causes harm to humans or animals). This focus is corroborated by the agreements stemming from this period, namely the United Nations Convention on the Law of the Sea, MARPOL, and the Basel Convention. The focus has now, however, shifted to seafood with microplastics ending up on our dinner tables as well as entangled in marine wildlife (Borja and Elliott, 2019). This type of research has set the tone for human emotion in the plastic arena, where citizens react to eating and visually seeing the harm of plastic in the global environment. 
These voices in the research community have overwhelming made a substantial contribution to the scientific literature around plastics. With new research on the topic being published continuously, it has become easier to understand the biodiversity, ecological, and health effects of plastic on the marine environment and human health. The focus has now, however, shifted to how this global crisis will be solved from a governance perspective (Vince and Stoett, 2018). The fragmented nature of past agreements is neither efficient nor effective paths for halting plastic pollution. We argue that a new legally binding agreement, whose pre-negotiations started in 2017 at the United Nations Environmental Assembly (UNEA) 3, is our current only concrete path toward an internationally legally binding instrument (ILBI) for curbing plastic pollution. Although plastic pollution is perceived as a marine only issue for many, it originates from a failure to control our land-based waste (Raubenheimer and McIlgorm, 2018b). As such, an ILBI must address all sources of pollution, both from land and sea. At the time of writing 143 countries have signaled their support for mandating negotiations on a globally binding plastic agreement ${ }^{1}$, which has also been welcomed by industry, government and NGOs, signaling that the time to act is now.

\section{PLASTICS ON THE GLOBAL STAGE}

Worldwide plastic production rates have reached well over 380 million tonnes in 2018 alone (Ritchie and Roser, 2018). This number has grown exponentially during the COVID19 pandemic where production and consumption has been intensified from the use of disposable personal protective equipment (e.g., face masks) and takeaway containers to avoid cross-contamination (Tessnow-von Wysocki and Le Billon, 2019). No recycling system can handle the utter volume of plastic we accumulate. In 2015, 320 million tonnes of plastic waste were generated, from which $24 \%$ was incinerated and $58 \%$ landfilled or discarded (Geyer et al., 2017) in the environment. The problem is only growing, with scholars stating how increasingly difficult it has and will become to clean up the waste leaked into the environment which is expected to reach up to 53 million tonnes in 2030 alone (Borrelle et al., 2020). This plastic crisis is estimated to cost the world's economies nearly 2.5 trillion USD each year alone (Beaumont et al., 2019). Currently, the only long-term and comprehensive solution to the plastic crisis is to tackle it at its roots and end the constant flow of plastic to the marketplace and ultimately the ocean. Plastic extends beyond the capacity of any one nation to solve, as our oceans create a planetary cross-border crisis of marine pollution. Experts argue that the best solution can be found in the form of a globally binding agreement or an ILBI [Carlini and Kleine (2018), Dauvergne (2018b), Raubenheimer and McIlgorm (2018b), Tiller and Nyman (2018), Vince and Hardesty (2018), Tessnow-von Wysocki and Le Billon (2019)]. Our current agreements, situated at different governance levels and fragmented at best, are neglecting to make actors legally and

${ }^{1}$ WWF has complied a 'Global Plastic Navigator' which demonstrates each country that has publicly called for a new legally binding agreement as well as countries that agree to consider an agreement. Available at: https://plasticnavigator.wwf.de/ financially accountable, as well as failing to fully address the crisis on a global scale.

In light of this, we conducted a systematic peer-reviewed literature review to examine the various approaches that the scientific community have developed on how to best govern plastic pollution to assess the potentials for success for a future ILBI if initiated by UNEA in 2022. Systematic reviews provide the ability to gather evidence, so policymakers can make informed decisions. We made the methodological choice to utilize only peer-reviewed articles that examine the plastic crisis on a global scale. This type of systematic review has not yet been conducted and we therefore believe it is of utmost importance to publish before the upcoming plastic treaty negotiations talks begin at UNEA 5.2, planned for February 2022 in Nairobi, Kenya. Civil society has numerous valuable reports on the same topic, and we therefore saw the need for an academic contribution to the literature, which will provide future scholars with the relevant references in the global plastics governance arena. UNEA is unique in that it is currently the worlds highestlevel decision-making body on the environment. Moreover, in May 2021 both Peru and Rwanda announced they would table a resolution at UNEA 5.2 to establish an intergovernmental negotiating committee to begin developing an ILBI for global plastic governance (UNEP, 2021).

Borja and Elliott (2019) may have been right when they asked the question "when will we have enough papers on microplastics and ocean litter"? Yet, we argue that media and society has been too focused on the crisis and not the solution for moving forward, and as such, there still is not enough. Plastic pollution has been a growing discussion in the media and successively in citizen opinions over the past decades (Tiller et al., 2019). For this literature review, we therefore chose to focus on aspects relating to the governance of not just pollution, but the product itself throughout its lifecycle, instead. To solve the plastic crisis, we argue that a comprehensive ILBI must be adopted that precisely addresses the comprehensive life cycle governance need of plastics.

\section{METHODOLOGY}

This review contains all available peer-reviewed academic literature encompassing global plastic governance found via Google Scholar up until July $4^{\text {th }}, 2021$. To date there are no holistic systematic peer-reviewed literature reviews which present an overview of the key authors and global actors effecting and driving global plastic governance. This review will aid in preventing replication of research, while highlighting the areas of focus laid out by key authors in global plastic governance. We believe the timing of the article is important given the timeline of the UNEA discussions on how to solve the world's plastic pollution crisis culminating after having been ongoing since its first meeting in 2014. In recent years this has developed into a more coherent need to produce a concrete global agreement and we believe this review will provide a holistic guide to the research arguments on said topic and highlight where we need more focused attention. 


\section{Literature Search}

We collected and assessed our data using a six-stage process as laid out by Pacheco-Vega (2018).

1) Key citations and authors

2) Citation tracing process

3) Mind map of key authors and topics

4) Choose 3-7 articles per topic and 3-5 per subtopic

5) Read and;

6) Expand mind map

The first step was to identify the key authors and citations within the wider debate on plastic governance globally. We utilized Boolean search citation tracing via Google Scholar by searching the words "plastic" AND "governance" OR "management." This search contained 241,000 results. To guarantee the literature encompassed the marine environment, where our initial interest laid, whether the pollution source is marine or land-based, we then updated our search to "plastic governance marine" OR "oceans." This provided more precise articles and included 40,600 results as of July 2021 . We then begun step two which we combined with step three of Pacheco-Vega's process which involved citation tracing and mind mapping. As we were two researchers working on this review, one of us was on the computer reading out and citing the authors and articles while the other was creating a first rough draft of our mind map as seen below in Figure 1.

\section{Limitations}

Despite the effort to provide a comprehensive review of the peer-reviewed body of literature, this review, like many, has its limitations. First, only documents written in English were included in this review, leaving out articles in other languages that could be highly relevant for these purposes. Second, the review only utilized peer-reviewed articles. Our search found several conference proceedings, dissertations and gray literature documents that were deliberately not included among our results. The gray literature specifically from civil society and industry stakeholders has significantly impacted the discourse around a globally binding plastic treaty. However, for the means of this review we chose to examine the academic case for such a treaty. The gray literature especially stemming from WWF and the Ellen MacArthur Foundation arguably leads to additional insights that are valuable in-and-of themselves such as The Business Case for a United Nations Treaty on Plastic Pollution and various others (Ellen MacArthur Foundation, 2020; WWF et al., 2020; WWF, 2021). Third, the academic literature was searched using only one database, Google Scholar. Although this database covers a significant majority of international peer-reviewed journals, other, more specialized databases might cover other potentially relevant journals. Using Google Scholar was a methodological choice as it is highly accessible to all, and recent studies have highlighted how databases such as Web of Science and Scopus have limited coverage of the social sciences and humanities (Mingers and Meyer, 2017). Moreover, Google Scholar has been highly underestimated and according to a study by Gusenbauer, it is currently the most comprehensive academic search engine
(Gusenbauer, 2019) and therefore the reason behind its use within this literature review.

We used mind mapping methodology as strategic research and writing tool. To ensure the results were global in focus, we excluded all peer reviewed articles and regulations that were country or region specific (such as case studies on plastics governance solutions in $\mathrm{x}$-local community in Norway or Single Use Plastic regulations in the EU), technological solutions focused (waste-water treatment plants or recycling technology for example), and/or did not have a clear focus on governance of plastic pollution in the abstract. The reason for this was to emphasis the global crisis of plastics, although regional regulations are positive in their nature, the pollution happens on a global scale and therefore needs global solutions. We also excluded any results that had to do with the life cycle of plastics in terms of chemistry and biology as these topics did not focus on global plastic governance, which was often alluded to in the conclusion section as "something that should be initiated." After the first 50 pages of reviewing results on Google Scholar, we reached a saturation where no additional articles of relevance directly related to global plastic governance were found. We therefore decided to end the online search while continuing to cross check the reference list of articles we had already established as relevant to find literature that may have been missed in our Google Scholar search. By cross referencing the articles reference lists, we were indeed able to find 19 new peer reviewed articles that our search results had missed, bringing the total to 64 articles. Overall, we had 193 authors \& co-authors writing about the topic of global plastics governance. Of those authors only five were reoccurring lead authors of one or more articles (Borrelle 2, Dauvergne 3, Raubenheimer 5, Rochman 2, Simon 2, Vince 3, Tiller 2, Stoett 1, Hardesty 1, Carlini 1) while others were also co-authoring on more than one article (Hardesty 4, McIlgorm 4, Wilcox 2, Vince 2, Stoett 2, Rochman 2, Costa 2, Carlini 2, Urho 2).

After having a full overview of the peer-reviewed literature on global plastic governance the next step was to narrow down the key authors and which topic or subtopic their articles belonged in. Our findings were then sorted in a database that matched each author and article to one of our four key topics (Overview, top-down driven, bottom-up driven, treaty solution). Once categorized, we read the abstracts of each followed by an in-depth read of each article. While doing this, we also assessed the open access availability of all the full text publication. Though we belong to a research institute that has wide access to scientific publications, we still had to purchase three sources of literature as they were not available on open access. The remaining 67 articles were all either open access or available through our institution's subscriptions. The sources included are listed below:

- Barboza, L. G. A., Cózar, A., Gimenez, B. C., Barros, T. L., Kershaw, P. J., and Guilhermino, L. (Barboza et al.). Macroplastics pollution in the marine environment. In World seas: An environmental evaluation (pp. 305-328). Academic Press. - Paid 30.00 USD

- VanderZwaag, D., and Powers, A. (2008). The protection of the marine environment from land-based pollution 


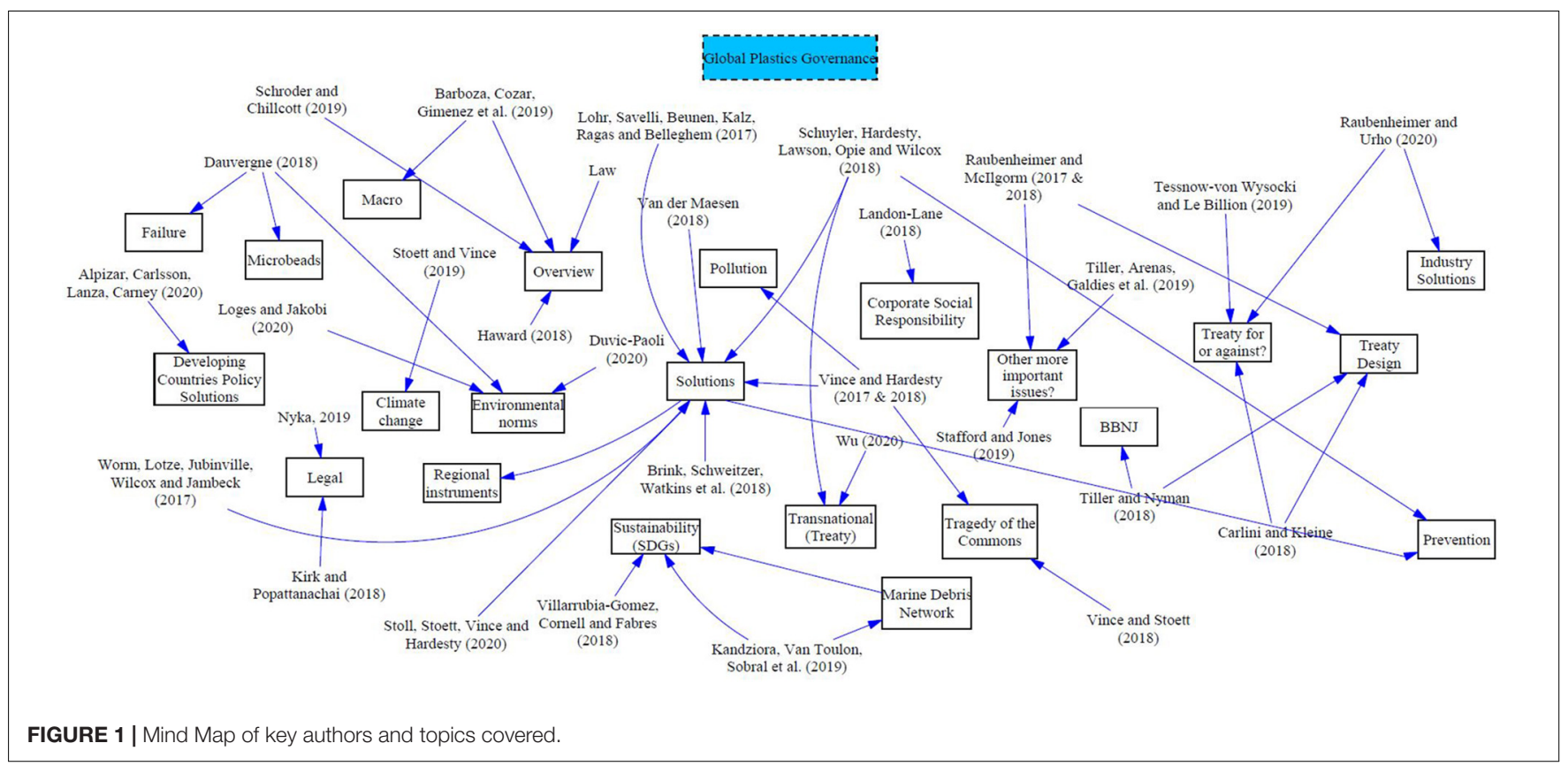

and activities: gauging the tides of global and regional governance. The International Journal of Marine and Coastal Law, 23(3), 423-452. - Paid 35.00 USD

- Schröder, P., Anantharaman, M., Anggraeni, K., and Foxon, T. J. (Eds.). (Schröder and Chillcott). The circular economy and the Global South: Sustainable lifestyles and green industrial development. Routledge. - Paid 45.00 USD

\section{Data Collection}

The data collected from the study was organized into a Microsoft excel spreadsheet. The following information was collected for each article we included in this review and organized by category (overview, top-down, bottom-up solutions):

1) Digital object identifier (DOI)

2) Authors

3) Year

4) Journal type

5) Title

6) Summary of main findings

7) Type of article

8) Key words

After the search was complete, we narrowed down the key journals which have published articles on global plastic governance, as seen in Table 1.

Next, we analyzed the key years of publications on global plastic governance. As shown in Table 2 below the year 2018 brought global plastic governance to the forefront of discussion in research discussion. The UNEA 2017 first talks of truly establishing a global agreement on plastic waste could be hypothesized to have pushed the literature to the forefront.

In the following section, we examine and describe the results of the systematic review. First, we present our findings of each
TABLE 1 | The number of publications on global plastic governance in repeating journals.

\begin{tabular}{lc} 
Most prominent journals & Number of papers \\
\hline Marine policy & 9 \\
Marine pollution Bulletin & 4 \\
Environmental science and policy & 3 \\
Environmental science and technology & 3 \\
Global environmental politics & 3 \\
Frontiers in marine science & 2 \\
Environmental politics & 2 \\
Review of european, comparative and international & 2 \\
environmental law & \\
Science & 2
\end{tabular}

TABLE 2 | The number of publications per year contained within the scope of the review.

\begin{tabular}{lc}
\hline Year & Number of papers \\
\hline $2020-\left(\right.$ to July $\left.4^{\text {th }}, 2021\right)$ & 13 \\
2019 & 11 \\
2018 & 21 \\
2017 & 10 \\
2016 & 3 \\
2015 & 3 \\
Before 2015 & 3
\end{tabular}

of the overarching themes that were addressed throughout the articles. Next, we examine the common elements throughout each of our thematic areas, ultimately providing information on the best paths forward for a global agreement as identified by these articles. 


\section{RESULTS}

The following Figure 2 is our expanded Mindmap which provides an overview of where each article is categorized. It is important to note that these were organized by overarching themes as many articles provided information able to fall under various categories of this review.

\section{THE PROBLEM (OVERVIEW)}

In this first section of the review, we analyzed the peer-reviewed literature that provided contextual knowledge on the main drivers of plastic pollution, while also setting the scene for new international solutions (Figure 2- path 2 from left). The literature from our sample identified several issues regarding global plastic governance and the pollution brought forth through lack of a binding agreement with punitive procedures. A common theme throughout the literature was how our current international laws and agreements fail to match the scale and severity of plastic pollution (Chen, 2015; Dauvergne, 2018b; Haward, 2018; Vince and Hardesty, 2018; Schröder and Chillcott, 2019). Due to marine litter's complexity and inability to trace its origins and management process, authors suggest that for significant change to occur, a multilateral agreement on scale to the Montreal Protocol on Substances that Deplete the Ozone Layer would need to be enacted (Gold et al., 2014; Chen, 2015; Haward, 2018). The protocol has been widely renowned as it is considered the most successful multilateral agreement in resolving an environmental issue while also achieving global cooperation by attaining set targets. The international instruments, and current legislation in place now are nowhere near effective as they focus on prevention and mitigation (Borrelle et al., 2017). We argue that for a globally binding treaty to work it needs to account for all phases of plastics lifecycle (production, consumption, disposal, and contamination). The international efforts date back to the 1970s, and unlike the Montreal Protocol, five decades later the world is waiting for leadership to enact meaningful change on plastics. In Table 3 we lay out the current international agreements in place and their main inhibiting factors as to why they fail to address the plastic crisis on a global scale as identified by the authors reviewed (Haward, 2018; Landon-Lane, 2018; Raubenheimer and McIlgorm, 2018b; Vince and Hardesty, 2018).

Major deficiencies are found within regulation enforcement (national, international, and industry level) and cooperation, as well as overall waste management. Due to this lack of accountability, soft law (non-binding agreements) has dominated the plastic governance arena (Vince and Hardesty, 2018). Future guidelines, such as those up for discussion at UNEA 5.2 must clearly provide binding and punitive solutions, ones that also address production of plastic from land and not pollution that is simply ship based (Nyka, 2019). For example, UNCLOS (1982) uses phrases such as “. . Nations shall endeavor" or "best practical means..." which fails to tackle the crisis associated with adequate accountability and sufficient economic penalties

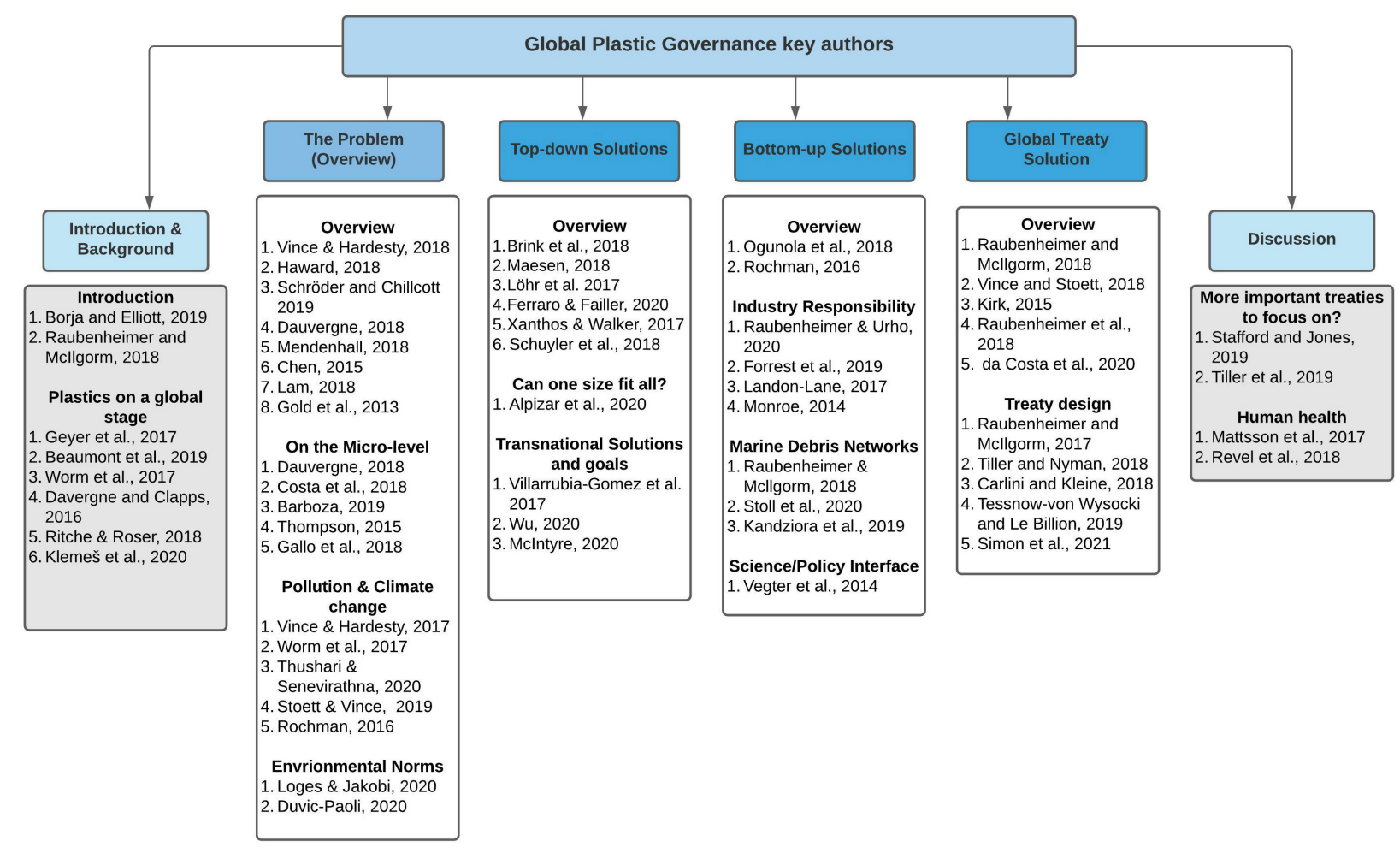

FIGURE 2 | Lucidchart demonstrating the final categories each article is placed in. 
TABLE 3 | Current international instruments related to Marine Plastic Pollution and their pitfalls.

\begin{tabular}{|c|c|}
\hline International instrument & Main pitfall \\
\hline $\begin{array}{l}\text { United Nations Convention on the } \\
\text { Law of the Sea (UNCLOS) }\end{array}$ & $\begin{array}{l}\text { No specific obligation to marine litter and } \\
\text { fails to address accountability and penalties }\end{array}$ \\
\hline Annex $V$ of MARPOL $73 / 78$ & $\begin{array}{l}\text { Lack of enforcement and monitoring } \\
\text { capabilities - only marine based }\end{array}$ \\
\hline London protocol & $\begin{array}{l}\text { Not globally binding - fails at enforcement \& } \\
\text { monitoring }\end{array}$ \\
\hline $\begin{array}{l}\text { United Nations Environmental } \\
\text { Program (UNEP) }\end{array}$ & $\begin{array}{l}\text { Programs related to plastic, i.e., Regional } \\
\text { seas program are mere guidelines }\end{array}$ \\
\hline Honolulu strategy & Volunteer-supported, not legally binding \\
\hline $\begin{array}{l}\text { United Nations Environmental } \\
\text { Assembly (UNEA) }\end{array}$ & Currently only a non-binding resolution \\
\hline $\begin{array}{l}\text { Basel convention - Including the } \\
2019 \text { plastics amendments }\end{array}$ & $\begin{array}{l}\text { Implementation failures, claims to make the } \\
\text { global trade on plastic more transparent. } \\
\text { Still not all plastics are declared hazardous }\end{array}$ \\
\hline Stockholm convention & $\begin{array}{l}\text { The scope of the Stockholm Convention } \\
\text { covers only a fraction of hazardous plastic } \\
\text { additives. }^{2}\end{array}$ \\
\hline
\end{tabular}

(Gold et al., 2014). These terms also offer mere facilitative bottom-up procedures that do not ensure compliance.

\section{Economy of Change?}

Vince and Hardesty (2017) examine the value of economic and market-based instruments within the framework of a global agreement. Third party certifications and a "Plastic Stewardship Council" (Landon-Lane, 2018) are argued to provide impactful policies that are not solely self-regulated, so long it is industry endorsed, though Misund et al. (2020) found in a study from three European nations that the consumer willingness to pay for such labels (plastic free for example) were inversely linked to political trust in the given country. The use of industry licensing with Extended Producer Responsibility (EPR) schemes are also identified as integral parts in future agreements (Monroe, 2013; Chen, 2015; Borrelle et al., 2017; Lam et al., 2018; LandonLane, 2018; Forrest et al., 2019; Schröder and Chillcott, 2019; Raubenheimer and Urho, 2020) and are examined later in this review as a separate approach. These schemes could force producer and/or manufacturers to pay the clean-up and recovery fees for discarded plastic, however, they must hold producers accountable for the previous years of pollution as argued by Monroe (2013). Moreover, the lobbying efforts backed by the plastic industry are hindering the political effort to implementing these schemes. Schröder and Chillcott (2019), describe the worldwide efforts plastic producers and manufacturers have in halting EPR schemes and taxes on virgin polymers. Economies of change should include binding agreements to end fossil fuel subsides (Borrelle et al., 2017), which could help bring the price of virgin plastic up and generate a stronger industry for recycled plastic.

\footnotetext{
${ }^{2}$ Aurisano et al. (2021) states that currently the Stockholm Convention is our only agreement in place to regulate the production phase of plastic. It fails in that it only includes a limited amount of chemicals prohibited from the list, while more than 1500 chemicals used in plastic production have been identified as harmful, yet not prohibited.
}

The buck does not stop current ideas on EPR schemes though. The previous two decades have proved that governing the industry is increasingly difficult. Profit and industry interest are far above the will of the people, from 2005 to 2018 more plastic was produced than any other time in history combined (Geyer et al., 2017). Moreover, regardless of bottom-up governance improvement efforts, there is currently a lack in keeping pace with the rising environmental costs associated with globalization of plastic waste (Dauvergne, 2018b). Packaging waste from plastic generates substantial negative externalities, and in 2014 marine plastic litter was conservatively estimated to costs the world 13 billion USD per year, a number now estimated to be closer to 2 trillion USD per year (Beaumont et al., 2019; Schröder and Chillcott, 2019). Merely recycling our way out of this disaster is not expected to provide meaningful impacts. However, changing economies will require global funds to assist nations with underdeveloped waste and recycling system, this framework could be similar to that of the United Nation Framework Convention on Climate Change's fund (Borrelle et al., 2017).

\section{Missed Opportunities}

Arguing that waste management and clean-up are serious governance solutions has previously been endorsed (Mendenhall, 2018). Other scholars also consider that the governance aspects of plastic are so diverse it will be nearly impossible to govern on a global scale (Dauvergne, 2018b). Dauvergne also stated that the endless rise in production and our growing consumption of plastics is leading to obscured views of responsibility. The missed opportunities lie within the extreme complexities and difficulties we currently face in documenting pollution and assigning responsibility, which must be addressed in a global agreement. Currently, however, international law is severely limited as the agreements in place poorly acknowledge that $80 \%$ of marine plastic debris originates from land not the sea (Simon and Schulte, 2017; Vince and Hardesty, 2017; Landon-Lane, 2018). Finally, China's National Sword policy, which banned the importation of waste, demonstrated that if we remove barriers to investment and open new markets for recycling, we can protect the environment, public, global markets, and industry itself (Raubenheimer et al., 2018). This is a solution that is currently not utilized by the rest of the world.

\section{Proposed Solutions}

Vince and Hardesty summarized in the "tragedy of the plastic commons" (Vince and Hardesty, 2018) that there is a need for a holistic governance approach in order for us to be able to actually reduce our plastic waste, as we are currently facing uncontrollable exploitation of our oceans (Haward, 2018). The tragedy can, however, be solved with effective global policy and public will, and lead to a highly anticipated global agreement to drive change (Vince and Hardesty, 2018). There is a need for coherent international action with measurable targets, these actions could include bringing back the 1964 "common heritage" of our interconnected seas and oceans by modeling the agreement after the Montreal Protocol (Haward, 2018). Hardhitting industry regulations on the domestic level as well as scaled up international treaties are seemly the only way out 
of the plastic crisis (Raubenheimer and Mcllgorm, 2017; Worm et al., 2017; Dauvergne, 2018b). The agreement would need to cover all aspects of the value chain, Starting with producers. Offering producers incentives to design better products and making recycled materials cheaper by taxing virgin plastics is a good place to start.

It is important to remember though that international agreements take time to develop and implement (Haward, 2018). For a plastic ILBI to actually create change, important global state actors like the United States (US), China, and India must be onboard - both as major plastic users and producers (Schröder and Chillcott, 2019). Therefore, achieving EPR and hindering consumer waste will be vital for inclusion in future agreements. In the end, authors also emphasize three aspects that need to be considered - the producer, the consumer, and the government and all need to take responsibility in different ways, from ensuring the safety of the product, following the three Rs (reduce, reuse and recycle) and establishing an international convention for the tracing and governance of plastic pollution (Law, 2017; Lam et al., 2018).

\section{On the Micro-Level}

The literature continues to examine the harmful impacts of how plastic breaks down and degrades in our oceans. Microplastic pollution has been written about in terms of the harmful widescale effects on marine biotas and ecosystems, and more recently, the possible effects on human health (Dauvergne, 2018a; Gallo et al., 2018; Lam et al., 2018; Barboza et al., 2019; da Costa et al., 2020). In 2015 you could still regularly find products, typically for personal care, that included microbeads (toothpaste, face wash, etc.). At the time scholars began debating the difficulties associated with wide-scale beach clean-up initiatives and then began to stress the best solution to fighting plastic pollution was source reduction (Rochman et al., 2015). This has worked on a national level thus far in terms of banning microbeads and introducing plastic bag bans (Dauvergne, 2018a). The time has now come to determine wither or not the same type of policy would translate to the global scale. As the crisis of plastics is on a global scale, only global solutions will be able to solve it.

Microbead researchers have sounded the alarm to the downsides of EPR schemes as Dauvergne, Dauvergne (2018a) emphasized. Companies most responsible for microbead pollution are the ones who benefit the most from claims of environmental sustainability and corporate responsibility, as little to no financial penalties are in place for the pollution they caused before the ban (Dauvergne, 2018a). Incorporating elements from the microbead ban will need to take corporations and profiteers into account and create schemes to make producers and manufacturers pay for past pollution. A final thought when assessing future governance by examining past microplastic pollution comes from Thompson (2015). Thompson believes there is an inevitability regarding microplastic in the environment, regardless of new regulation. He argues that even if we stop all new forms of plastic from entering the ocean today, fragmentations of already ocean bound plastic items will continue to degrade and break into smaller pieces in the decades to come (Thompson, 2015). Due to previously insufficient legislation, future governance mechanism must be inclusive, multi-sectoral, and acceptable by stakeholders (Barboza et al., 2019), leading to a complete overturn of the way we think of plastic.

\section{Plastic Pollution and Climate Change}

The research community is seeking to add plastics to the same level of urgency as climate change is addressed. Although some scholars believe that the plastic crisis is addressed too much by science (Stafford and Jones, 2019; Tiller et al., 2019), the two are, in fact, inadvertently intertwined. Plastic pollution disrupts our worlds food chains, ultimately upending our oceans ecosystems from regulating themselves from the disaster of climate change (Stoett and Vince, 2019). Both tragedies are interlinked and need to be considered when discussions resume on either of the two. A reduction in our plastic resource utilization is considered one of most viable solutions to plastic pollution as no legally binding international agreements are available. Similar to that of plastic pollution and climate change, successful governing of the former will require holistic approaches to address pathways of pollution knowledge gaps (Vince and Hardesty, 2017). The crisis is comparable, wither it be to modeling the treaty after the Montreal Protocol, or taking swift action like in silent spring (Worm et al., 2017) as a first step.

\section{Environmental Norms}

Dauvergne (2018b) examines how environmental norms have power, and change depending on what is happening in our world. For example, when science is strong, activism is high, and political and corporate resistance is weak. Our current values and behaviors around plastic do not align with coherent governance mechanisms despite that science is strong (Loges and Jakobi, 2020). Loges and Jakobi argue that regardless of researchers proposing an international agreement, it will not overcome the de-centeredness of norm dynamics as well as agencies ineffectiveness to monitor and govern. Moreover, Duvic-Paoli (2020) argue that our environmental norms should be based on the foundational prevention principal, meaning environmental damage is better avoided than repaired. Principals like these can foster creative and effective law-making as well as adaption to current legal frameworks. Policies like these must be implemented at the national level, literature on top-down solutions are examined in the next section.

\section{TOP-DOWN SOLUTIONS}

Though there is an abundance of work in the academic literature from a governance perspective that focuses on the problem itself, some also examine solutions. The main category we placed the literature in was that of top-down driven solutions (Figure 2, path 3 from left). Scholars are in consensus that top-down driven solutions on plastic governance overwhelmingly requires systematic change at the local, regional, and national levels as they will be enforced with strong regulatory obligations. Various authors argue that the best form of change is shifting to a circular 
based economy (Löhr et al., 2017; Ten Brink et al., 2018; Forrest et al., 2019). The circular economy model, if implemented in a global agreement, would minimize the overuse of resources as well as limit carbon emissions, waste, and pollution. An overturn of society will seem daunting until states recognize a circular economy would create jobs, boost economic competitiveness, provide resource savings, and prevent harmful waste such as plastic for entering our oceans. Lack of political harmony within and across borders is inhibiting these efforts of change (van der Maesen, 2018) without understanding that the responsibility falls on all states to act (Ten Brink et al., 2018).

National implementation and compliance on a global agreement must be fully integrated with domestic policies (Vince and Hardesty, 2017). However, authors Ferraro and Failler (2020) argue that there is a complex set of factors that prevent nations from implementing international agreements on the ground. To overcome these obstacles, coherency across national policies will require adoption strategic plans and involvement of stakeholders in the process from the ground up (van der Maesen, 2018; Ferraro and Failler, 2020; Wu, 2020). Strategic plans from the top should therefore include building up waste management infrastructure on a national and regional basis, while including stakeholders in the transformation process to ensure that new infrastructures work for all citizens. These infrastructures must incorporate economic incentive. One such incentive has been documented to reduce plastic pollution to the ocean is container deposit legislation (CDL) (Schuyler et al., 2018). The amount of plastic pollution found in coastal areas is $40 \%$ lower when CDL are in place. The simple method of charging consumers extra when they buy a plastic bottle, only to return said investment through bottle schemes is considered vital for all nations to avoid heaps of plastic accumulating in our environments.

\section{Can One Size Fit All?}

Policies at the top level have also thus far been insufficient (Löhr et al., 2017; van der Maesen, 2018). This must change as a global agreement needs to be able to be translated to national and regional levels for successful implementation and compliance. This will require top-down driven change while simultaneously pushing for citizen behavioral change (Ogunola et al., 2018). What happens when change for developed nations in a global agreement does not work the same as in developing ones? We turn to Alpizar et al. (2020) to understand the various problems that developing nations face with equality in global agreements, which was one of the few articles found within the methodological literature search.

When a global agreement on plastic governance gets on the global governance agenda, it needs to not only include attainable solutions, but it must consider how plastic becomes used, discarded, and renewed at national levels worldwide. A challenge identified by Simon et al. (2021) is that waste pickers have become a common job in less developed countries, leading to employment of otherwise unemployed citizens. We argue that a global agreement must take this into consideration and enhance the jobs available for recycling facilities in all countries. The one size fitting all dilemma must also consider how plastic pollution arrives from various countries, with several explanations for pollution leakages depending on where you live (Alpizar et al., 2020). For example, Tanzania has an 84\% rate of inadequately managed plastic waste and resorts to open burning and dumping of said waste. In Vietnam plastic leaks from agriculture and aquaculture activities, which overwhelms rivers, pushing plastic out to the sea during the rainy season (Alpizar et al., 2020). India on the other hand, has high recycling collection rates, yet low quality wastewater treatment and insufficient landfills, leaving plastic to leak into local and eventually marine environments. Although there is no one size fits all guideline for each country, a global agreement would need to consider the challenges between average incomes and regions. This information should be used to set up a fund to implement the agreement worldwide. Diversity of knowledge, cultures, and indigenous perspectives must therefore have a seat at the negotiation table.

\section{Transnational Solutions and Goals}

Löhr et al. (2017), argue that the framework involving DriverPressure-State-Impact-Response can be used as a management tool to map out potential responses to plastic pollution and provide solutions for sustainable development. The UN's Sustainable Development Goals (SDG) are argued to provide a means of measurement and compliance when a global agreement is in place. Marine plastic pollution should then be linked to justice issues as it is interconnected to the SDG goals (Stoett and Vince, 2019).

Transnational governance is in fact argued by some scholars as the only true answer to the plastic crisis (McIntyre, 2020; $\mathrm{Wu}, 2020)$. International agreements as they stand today do not provide sufficient governance mechanisms to address marine plastic pollution. Wu (2020) for example found that overall, international success depends on domestic laws and policy reforms. States must adapt and enforce current global legally obligating procedures to better transition to a more demanding agreement when one arrives. The legal landscape of plastic governance is furthermore very fragmented (Nyka, 2019; McIntyre, 2020) and would benefit from cohesion between national and supranational agreements already in place.

\section{BOTTOM-UP DRIVEN SOLUTIONS}

In this section we step away from the ILBI angle and examine some of the bottom-up solutions to a global plastic agreement that are discussed in the peer-reviewed literature as well such as certifications, industry driven solutions, corporate social responsibility, and networks (Figure 2, path 4 from left). In terms of prevention and regulatory strategies, Ogunola et al. (2018) considered ecolabeling (private companies, and voluntary scheme - for public acceptance and marketability) and imposing fees (i.e., on plastics bags) as some of the most important drivers within bottom-up solutions. Market based strategies are also an integral part of Xanthos and Walker (2017) proposed solution. Rochman (2016) created a scenario to help describe the benefit of bottom-up driven solutions as followed; If a water pipe in your 
basement were to burst, would you turn off the source of water, or simple mop up the mess while water continues to spew? While swift action (turning off the tap) is an important first step, it will take a variety of mixed solutions (mopping up the mess) to be built into a global agreement.

\section{Industry Responsibility}

One of the arguments is that the first of these solutions should be industry based, where consumers and governments apply pressure on the plastic industry. Industry focused governance strategies must include an EPR scheme, where producers, manufacturers and importers have a legal responsibility to ensure circularity and recapture of their products at the end-of-life stage. Incentives are also mentioned as a mitigation method for ensuring that products are recycled or disposed of responsibly, whether it concerns bottles, plastic bags or other items for single-use -even fishing gear (Monroe, 2013; Landon-Lane, 2018; Forrest et al., 2019). Incentives generally include wanting to adapt to consumers demands, but may include support from governments to transition into solely manufacturing sustainable plastic (Landon-Lane, 2018). Generally, behavioral change at the individual level is what is critical to curb the flow of plastics into the ocean (Ogunola et al., 2018), but it will take industry action to curb the crisis as a whole.

The literature has been stagnant on what bottom-up actors must do without including innovative solutions to achieving goals, until Raubenheimer and Urho (2020) examined the possibility of a global EPR scheme. Previously the idea was discussed at the national level, however, it is now important to rethink the role of industry withing a global agreement. In general, EPR schemes force producers to be responsible for the entire lifecycles of the products they produce, both financially and in other cases physically. A global EPR scheme would be developed through global standards to make products more sustainable and easier to reuse. These schemes must also, at the global level, provide incentives for producers to build better designs into their products (Raubenheimer and Urho, 2020). Moreover, EPR schemes also must include financial penalties for the pollution they caused before an agreement is in place (Dauvergne, 2018a). Others argue that we must evolve EPR schemes to comply with a global audit system, able to protect against fraud in the system by implementing blockchain technologies to track provenance (Forrest et al., 2019). These schemes must also be obligatory and include monitoring on various levels, with reporting including both quantitative and qualitative data sets. If these measures are implemented it will help transform the entire value chain of plastics, create competitive advantages to producers and retailers, create jobs, and ensue healthy ecosystems and livelihoods (Simon et al., 2021).

\section{Marine Debris Networks}

Marine debris networks (MDN) could play another key role in stopping marine plastic pollution and creating new policies for prevention (Kandziora et al., 2019). Instead of traditional profiteering ways, these networks do not pursue profit. Instead, they provide platforms for engagement and education. Marine debris networks exist in multiple countries around the world reaching nearly every continent. The approach is bottomup with networks active on not only regional and national levels, but also globally. This integrated approach works well as the global networks can reach policymakers, researchers, and industry, the national and regional networks are able to create change locally by engaging with stakeholders (Kandziora et al., 2019). Marine debris networks also have their pitfalls though. First and foremost, by including the word "marine" it automatically excludes the importance of plastic waste from land. Moreover, without setting up collaborative platforms to meet and share information, the networks can fail to communication relevant information. To overcome this, like the EPR global scheme, marine debris networks may require a global fund. Multilateral agreements considered successful on societal and behavioral change on a global scale are those who have funding mechanisms and monitoring compliances (Raubenheimer and McIlgorm, 2018a).

\section{Science-Policy Interface}

The field researching plastic pollution is vastly distinct, ranging from marine biologist, chemist, geologist, social and political scientist, and various others. By having such diverse research, the underlying issues of plastic pollution, is brought home, regardless of if we live on the coast. Vegter et al. (2014) has documented how science brought us to where we are today with discussions soon starting on a global plastic governance agreement. Any governance solution will require a broad range of actors from the ground up on multiple levels of policymakers, industry, and stakeholders. The years following an agreement a framework must be in place as a science-policy interface must support the transfer of knowledge between the expert community and policymakers (Simon et al., 2021).

\section{GLOBAL AGREEMENT AS A SOLUTION}

The literature, however, has landed on - rather than topdown - or bottom-up solutions exclusively attempting to curb plastic pollution, there being a need for an ILBI to address the entire life cycle of plastic (Figure 2, path 5 from left). The solution to stop plastic pollution inevitable making its way to the sea, is not observed in recycling alone, or banning plastic bags in "x country." Recycling rates of plastic also varies geographically and accounting to the type (Hopewell et al., 2009). The systematic societal change as examined in the previous section will require a complete 180-degree transformation in the way products are designed. To date products have been designed with our throw-a-way culture, without taking the circular economy into consideration. Food packaging most typically includes multiple layers of materials (I.e., aluminum, plastic, paper, etc.) which has become a nightmare in the recycling industry. Due to lack of regulation and legally binding consequences for the disregard to the environment, most plastic packaging is only for single-use and therefore does not currently have market post consumption. Meanwhile, consumers have kept a good consciousness by believing anything with the recycling 
symbol indicates it can be recycled. The recycling industry has come up with a name to describe consumers who believe all types of plastic are recyclable, "wishcycling". ${ }^{3}$ A globally binding treaty as a solution to the plastics crisis will require adaptive changes to products from their design stage, and enforcement programs to incentivize compliance, while deterring non-compliance (Tessnow-von Wysocki and Le Billon, 2019). By changing the way products are designed on a global scale, new markets for recycled materials will arise and in turn create jobs across the world.

As explored throughout the literature in each section of this review, the plastic crisis has no chance of an equitable resolution without a global an ILBI. Various authors encourage us the draw on the prosperities and pitfalls of agreements of the past when creating a new one (Dauvergne, 2018b; Raubenheimer and McIlgorm, 2018b; Tiller and Nyman, 2018; Tessnow-von Wysocki and Le Billon, 2019). Lessons can be learnt from swift legally binding action as found in the Montreal Protocol, as well as the failures of recognizing plastic as a marine only problem, which leaves out the most treacherous source of pollution, land based. International policy has thus far been focused on oceanbased pollution (Raubenheimer and McIlgorm, 2018a) this has deviated attention from the mass amounts of pollution from land-based sources (Haward, 2018; Vince and Hardesty, 2018).

The time has passed to question if a global agreement is necessary, the extent of damage witnessed to our land and marine ecosystems has reached a critical tipping point. Plastic pollution is creating ecosystem-alterations within the chemical components of our planetary boundaries, that scientist believe are irreversible (Villarrubia-Gómez et al., 2018; Stoett and Vince, 2019). Though we still find gaps of knowledge as to the sources, pathways, and impacts of plastic pollution (Mendenhall, 2018), there is overwhelming evidence favoring an globally binding plastics treaty. This evidence transpires from science (Kirk, 2015) and it is our best weapon to understanding what knowledge is needed to design a treaty.

\section{Treaty Design}

As such, increasingly, authors are discussing treaty design when discussing the governance of plastics. An agreement would need to be met with complex interdisciplinary solutions (Stoett and Vince, 2019). A common idea for treaty design is adopting principles of responsibilities that are common between parties but differentiated (Carlini and Kleine, 2018; Tessnow-von Wysocki and Le Billon, 2019). This is considered within the contextual setting of the excessive levels of plastics being produced and consumed in developed countries and exported to developing countries - in addition, around, $50 \%$ of the waste generated in Europe is exported to areas where there is no waste management infrastructure. Still, or perhaps because of this, most leakage of plastic derives from middle-income states in Asia - and developing countries do not have the funds to invest in high level industrialized waste management infrastructure and recycling of plastics. As such, treaty design needs to take into account

\footnotetext{
${ }^{3}$ https://discardstudies.com/2021/02/15/on-wishcycling/
}

this skewed responsibility across the life cycle of plastics and respect both history and financial means of states so that participation is comprehensive in such a treaty (Tessnow-von Wysocki and Le Billon, 2019).

A global treaty must also link the issue to the global trade of plastics, while having financial mechanisms in place to support implementation measures. This is especially needed in developing countries - for example polluters pay options, must associate costs with recovery and disposal of products into a product it to begin with (Tessnow-von Wysocki and Le Billon, 2019). Moreover, due to the shortcomings in managing the global plastic industry, made up of small to large multinational companies (Raubenheimer et al., 2018) it has proved difficult to govern globally. Raubenheimer and Urho (2020) provide four goals that a new global agreement should entail. These include (1) sustainable waste management, (2) Elimination of problematic products, (3) Reduction in chemical hazards, and (4) Sustainable management of products.

We can achieve this by reducing production of virgin plastics (Simon et al., 2021), increasing profitability of postconsumer plastic, eliminating harmful chemicals, and providing legislative support to the recycling industry (Raubenheimer and McIlgorm, 2018b). Embedded within the agreement must be encouragement of private investment in collection and sorting centers, full recycling of post-consumer material, and shifting economies to the circular model (Raubenheimer and McIlgorm, 2018a). Raubenheimer ultimately stood out as the key author in the literature on designing a global plastic agreement. Some of the key objectives for design included the need to be followed up via measurable targets and caps on production and consumption ${ }^{4}$. Moreover, trade restrictions were found to help multinational agreements in treaty participation, control, and compliance (Raubenheimer and McIlgorm, 2018b; Tessnow-von Wysocki and Le Billon, 2019). In the end, when designing a treaty we must start at the source product design and virgin plastic materials. A treaty must include an agreed upon goal to reduce the production and consumption of virgin materials while circularizing economies to incentivize better product designs (Simon et al., 2021), which would in turn create more profitability in recycling centers (once hazardous chemicals are removed from plastics life cycle) especially when products are designed to be easily recycled.

\section{DISCUSSION}

The following section synthesizes the results of the peer reviewed global plastic governance literature as examined in this review (Figure 2, path 6 from left). In doing so, it offers critical reflections on researchers' findings, lack of attention in other fields, and recommended path forward actions in creating a global treaty.

${ }^{4}$ The agreement must set strict pollution prevention targets which will be implemented at the local, national, and supranational levels based on analyses of plastic flows (Simon et al., 2021). 


\section{Are There More Important Treaties?}

We identified gaps in the literature, mainly concerning how such an agreement can effectively and overarchingly be implemented on a global scale. The findings indicated that the literature is significantly lacking research from developing nations and their primary solution perspectives beyond that of case studies which were not included in the review. There was also a significant deficiency of literature on other topics within the subject of how to protect our environmental and ecosystems health. We then discovered authors who believe there are more important topics to address first. One of these authors examines why climate change and overfishing are more serious crises that have yet to be adequately addressed (Stafford and Jones, 2019). Despite their beliefs, the authors claim that they want to highlight how the media makes it convenient to focus on the plastic problem without taking systematic action to tackle climate change. Other literature has focused on ocean acidification as a separate and not equal issue that threatens our lifestyles (Tiller et al., 2019), an arguably invisible crises that is far more dangerous, and yet further away on the political agenda. The general public has become well-versed in the crisis of plastic, and the urgency deserves to be transferred to other threats that are less tangible and manageable, they argue. Overall marine debris and plastic pollution governance must either compete or cooperate with ocean warming and acidification (Raubenheimer and McIlgorm, 2018a; Tiller et al., 2019). The focus of plastic pollution is argued to not be marine based at all, as the pollution stems from land-based actions in the first place.

\section{Human Health}

We made the methodological decision to not include the vast literature on health and social justice in this review as it was not found in our literature search within the framework of this review. However, future studies could contribute greatly to the addition of the growing health concern plastic poses on society and ecosystems. Mattsson et al. (2017) for example demonstrates how for the first time, direct links between nanoplastic and brain tissues were able to observe behavioral disorders from the smallest plankton to the largest apex predator. Nanoplastics are not only believed to disrupt our environment and wildlife, but even believed to make their way up to the top of all food chains, Humans. Other scholars corroborate how this is not an ocean only problem, as nanoplastics can be found in our drinking water, land-based food sources, as well as the air we breathe (Revel et al., 2018). Research on how plastic effects human health can drive change on par with the Montreal Protocol, the unfortunate question needed to be asked is, when? Notwithstanding, environmental norms gain strength when an overwhelming amount of scientific evidence of the harm is consolidated, activism is intensified, and political and corporate resistance is weak (Dauvergne, 2018a). Therefore, research must continue to be funded to allow for better understanding of plastics effects on all walks of life to create an agreement that addresses the plastic crisis at the appropriate scale.

\section{CONCLUSION: A GLOBAL AGREEMENT AHEAD}

The literature on the need for a global solution is growing, and this review observed significant publications in 2018 following the third UNEA session in 2017. In 2021 at the fifth UNEA session the idea adopting a mandate to begin negotiations was widely accepted, and that mandate is expected at UNEA 5.2 in February 2022. Throughout this literature review we have examined the overarching crisis of plastic pollution and how our current international instruments in place are nowhere near effective enough to implement, enforce, and monitor a global agreement (Chen, 2015; Rochman, 2016; Borrelle et al., 2017; Dauvergne, 2018b; Haward, 2018; Lam et al., 2018; Mendenhall, 2018; Raubenheimer and McIlgorm, 2018b; Vince and Hardesty, 2018; Nyka, 2019; Schröder and Chillcott, 2019). The literature was also found to have strong links to plastics at the micro level, where scholars believe there are lessons to be learned in how governments took swift action on banning the material in consumer products (Rochman et al., 2015; Thompson, 2015; Dauvergne, 2018a; Gallo et al., 2018; Barboza et al., 2019; da Costa et al., 2020).

A legally binding global agreement on plastics will need to include market-based solutions, EPR schemes (which include recovering and recirculation into the circular economy), as well as active markets. With active markets we can include proven initiatives such as recycling material quotas, strategic targets, as well as full transparency for consumers on environmental impacts when purchasing products. We have a need for more than just descriptions of problems - we need solutions as well. As Borja and Elliott (2019) asked, "...what are the solutions to this land-based...problem given that we cannot put the genie back in the (non-recycled) bottle?" Various authors have also discussed what they believe an agreement would need to include in terms of its design (Carlini and Kleine, 2018; Raubenheimer and McIlgorm, 2018b; Tiller and Nyman, 2018; Stoett and Vince, 2019; Tessnow-von Wysocki and Le Billon, 2019). The overarching theme from the beginning was clear that an ILBI must learn from the prosperities and pitfalls of past environmental agreements and norms (Stoett and Vince, 2019; Loges and Jakobi, 2020; Thushari and Senevirathna, 2020).

Moreover, the topic of top-down solutions demonstrated that without action at the local, regional, and national levels an international agreement will be meaningless in preventing landbased pollution from entering the oceans $(\mathrm{Wu}, 2020)$. Solutions vary depending on where you live and what type of infrastructure your community already has in place, but change must be promoted across levels of governance (Löhr et al., 2017; Ten Brink et al., 2018). Transforming current linear economies into circular ones is an effective first step to the solution as well. Finally, diversity is of utmost importance to understand the needs and struggles between countries to implement what is to come on an international plastic agreement (Alpizar et al., 2020).

As such, the literature suggests that mixed solutions to a global agreement is an important step to building an agreement. One of the most prominent is industry responsibility 
(Rochman, 2016; Ogunola et al., 2018). Industry must be pressured with EPR schemes to ensure legal responsibility on products from creation to end of life (Monroe, 2013; LandonLane, 2018; Forrest et al., 2019; Raubenheimer and Urho, 2020). Incentives should be included to foster better products in the design stage, which will translate over to the recycling phase. In this sense it is vital to take the science-policy interface into account to include diverse research into how we can better design products to be easily recycled instead of the current, easily discarded. Moreover, marine debris networks can be key to ensuring global compliance withing an agreement. These networks, which aim to stop pollution from entering our oceans, aim to provide platforms of engagement and education through a bottom-up approach (Kandziora et al., 2019; Stoll et al., 2020). This should be included in future agreements to allow networking and collaboration between the various actors involved in the agreement creation.

Finally, for a globally binding plastic agreement to work it will require excellent design. There is no one size fits all guideline for the world. That means that an agreement must consider challenges between and within nations and include a fund to ensure no countries are left behind. This review identified scholars who have excelled in examining the best practices for designing a plastic agreement (Carlini and Kleine, 2018; Raubenheimer and McIlgorm, 2018b; Tiller and Nyman, 2018; Tessnow-von Wysocki and Le Billon, 2019; Simon et al., 2021). The authors

\section{REFERENCES}

Alpizar, F., Carlsson, F., Lanza, G., Carney, B., Daniels, R. C., Jaime, M., et al. (2020). A framework for selecting and designing policies to reduce marine plastic pollution in developing countries. Environ. Sci. Policy 109, 25-35. doi: 10.1016/j.envsci.2020.04.007

Aurisano, N., Weber, R., and Fantke, P. (2021). Enabling a circular economy for chemicals in plastics. Curr. Opin. Green Sustain. Chem. 31:100513. doi: 10.1016/ j.cogsc.2021.100513

Barboza, L. G. A., Cózar, A., Gimenez, B. C., Barros, T. L., Kershaw, P. J., and Guilhermino, L. (2019). "Macroplastics pollution in the marine environment," in World Seas: An Environmental Evaluation, ed. C. Sheppard (Amsterdam: Elsevier), 305-328.

Beaumont, N. J., Aanesen, M., Austen, M. C., Börger, T., Clark, J. R., Cole, M., et al. (2019). Global ecological, social and economic impacts of marine plastic. Mar. Pollut. Bull. 142, 189-195.

Borja, A., and Elliott, M. (2019). So when will we have enough papers on microplastics and ocean litter? Mar. Pollut. Bull. 146, 312-316. doi: 10.1016/ j.marpolbul.2019.05.069

Borrelle, S. B., Ringma, J., Law, K. L., Monnahan, C. C., Lebreton, L., McGivern, A., et al. (2020). Predicted growth in plastic waste exceeds efforts to mitigate plastic pollution. Science 369, 1515-1518. doi: 10.1126/science.aba3656

Borrelle, S. B., Rochman, C. M., Liboiron, M., Bond, A. L., Lusher, A., Bradshaw, H., et al. (2017). Opinion: why we need an international agreement on marine plastic pollution. Proc. Natl. Acad. Sci. U.S.A.114, 9994-9997. doi: 10.1073/ pnas. 1714450114

Carlini, G., and Kleine, K. (2018). Advancing the international regulation of plastic pollution beyond the United Nations environment assembly resolution on marine litter and microplastics. Rev. Eur. Comp. Int. Environ. Law 27, 234-244. doi: $10.1111 /$ reel. 12258

Chen, C.-L. (2015). "Regulation and management of marine litter," in Marine Anthropogenic Litter, eds L. Gutow, M. Bergmann, and M. Klages (Cham: Springer), 395-428. doi: 10.1007/978-3-319-16510-3_15 suggested targets including mixed methods of both topdown and bottom-up driven solutions will be best for a global agreement. The question now lays on the back of the UNEA 5.2 committee to finally begin negotiations of a global plastic agreement.

\section{AUTHOR CONTRIBUTIONS}

RT and EC contributed to conception and design of the study, organized the database, and wrote sections of the manuscript. EC wrote the first draft of the manuscript. All authors contributed to manuscript revision, read, and approved the submitted version.

\section{FUNDING}

The publication is part of a project that has received funding from The Research Council of Norway under project number 318730 PLASTICENE. The research has also received funding from the European Union Horizon 2020 Research and Innovation Programme under grant agreement no. 774499 - GoJelly project. This publication reflects the views of the authors, and neither the Research Council of Norway nor European Union can be held responsible for any use which might be made of the information contained therein.

da Costa, J. P., Mouneyrac, C., Costa, M., Duarte, A. C., and Rocha-Santos, T. (2020). The role of legislation, regulatory initiatives and guidelines on the control of plastic pollution. Front. Environ. Sci. 8:104. doi: 10.3389/fenvs.2020. 00104

Dauvergne, P. (2018b). Why is the global governance of plastic failing the oceans? Glob. Environ. Change 51, 22-31. doi: 10.1016/j.gloenvcha.2018. 05.002

Dauvergne, P. (2018a). The power of environmental norms: marine plastic pollution and the politics of microbeads. Environ. Politics 27, 579-597. doi: 10.1080/09644016.2018.1449090

Duvic-Paoli, L.-A. (2020). Fighting plastics with environmental principles? The relevance of the prevention principle in the global governance of plastics. AJIL Unbound 114, 195-199. doi: 10.1017/aju. 2020.41

Ellen MacArthur Foundation (2020). Global Commitment 2020 Progress Report. Cowes: Ellen MacArthur Foundation. Available online at: https://ellenmacarthurfoundation.org/global-commitment/signatory-reports

Ferraro, G., and Failler, P. (2020). Governing plastic pollution in the oceans: institutional challenges and areas for action. Environ. Sci. Policy 112, 453-460. doi: 10.1016/j.envsci.2020.06.015

Forrest, A., Giacovazzi, L., Dunlop, S., Reisser, J., Tickler, D., Jamieson, A., et al. (2019). Eliminating plastic pollution: how a voluntary contribution from industry will drive the circular plastics economy. Front. Mar. Sci. 6:627. doi: 10.3389/fmars.2019.00627

Gallo, F., Fossi, C., Weber, R., Santillo, D., Sousa, J., Ingram, I., et al. (2018). Marine litter plastics and microplastics and their toxic chemicals components: the need for urgent preventive measures. Environ. Sci. Eur. 30, 1-14. doi: 10.1186/s12302-018-0139-z

Geyer, R., Jambeck, J. R., and Law, K. L. (2017). Production, use, and fate of all plastics ever made. Sci. Adv. 3, e1700782.

Gold, M., Mika, K., Horowitz, C., Herzog, M., and Leitner, L. (2014). Stemming the tide of plastic marine litter: a global action agenda. Tulane Environ. Law J. 27, 165-203. 
Gusenbauer, M. (2019). Google scholar to overshadow them all? Comparing the sizes of 12 academic search engines and bibliographic databases. Scientometrics $118,177-214$

Haward, M. (2018). Plastic pollution of the world's seas and oceans as a contemporary challenge in ocean governance. Nat. Commun. 9:667. doi: 10. 1038/s41467-018-03104-3

Hopewell, J., Dvorak, R., and Kosior, E. (2009). Plastics recycling: challenges and opportunities. Philos. Trans. R. Soc. B 364, 2115-2126. doi: 10.1098/rstb.2008. 0311

Kandziora, J., Van Toulon, N., Sobral, P., Taylor, H., Ribbink, A., Jambeck, J., et al. (2019). The important role of marine debris networks to prevent and reduce ocean plastic pollution. Mar. Pollut. Bull. 141, 657-662. doi: 10.1016/ j.marpolbul.2019.01.034

Kirk, E. (2015). "Science and the international regulation of marine pollution," in The Oxford Research Handbook on the Law of the Sea, eds D. R. Rothwell, A. G. Oude Elferink, K. N. Scott, and T. Stephens (Oxford: Oxford University Press), 516-535.

Lam, C.-S., Ramanathan, S., Carbery, M., Gray, K., Vanka, K. S., Maurin, C., et al. (2018). A comprehensive analysis of plastics and microplastic legislation worldwide. Water Air Soil Pollut. 229, 1-19.

Landon-Lane, M. (2018). Corporate social responsibility in marine plastic debris governance. Mar. Pollut. Bull. 127, 310-319. doi: 10.1016/j.marpolbul.2017. 11.054

Law, K. L. (2017). Plastics in the marine environment. Annu. Rev. Mar. Sci. 9, 205-229.

Loges, B., and Jakobi, A. P. (2020). Not more than the sum of its parts: de-centered norm dynamics and the governance of plastics. Environ. Politics 29, 1004-1023. doi: 10.1080/09644016.2019.1703385

Löhr, A., Savelli, H., Beunen, R., Kalz, M., Ragas, A., and Belleghem, F. (2017). Solutions for global marine litter pollution. Curr. Opin. Environ. Sustain. 28, 90-99. doi: 10.1016/j.cosust.2017.08.009

Mattsson, K., Johnson, E. V., Malmendal, A., Linse, S., Hansson, L.-A., and Cedervall, T. (2017). Brain damage and behavioural disorders in fish induced by plastic nanoparticles delivered through the food chain. Sci. Rep. 7, 1-7. doi: 10.1038/s41598-017-10813-0

McIntyre, O. (2020). Addressing marine plastic pollution as a 'wicked' problem of transnational environmental governance. Environ. Liabil. 25, 282-295.

Mendenhall, E. (2018). Oceans of plastic: a research agenda to propel policy development. Mar. Policy 96, 291-298. doi: 10.1016/j.marpol.2018.05.005

Mingers, J., and Meyer, M. (2017). Normalizing google scholar data for use in research evaluation. Scientometrics 112, 1111-1121. doi: 10.1007/s11192-0172415- $\mathrm{x}$

Misund, A., Tiller, R., Canning-Clode, J., Freitas, M., Schmidt, J. O., and Javidpour, J. (2020). Can we shop ourselves to a clean sea? An experimental panel approach to assess the persuasiveness of private labels as a private governance approach to microplastic pollution. Mar. Pollut. Bull. 153:110927. doi: 10.1016/j.marpolbul. 2020.110927

Monroe, L. (2013). Tailoring product stewardship and extended producer responsibility to prevent marine plastic pollution. Tul. Environ. Law J. 27:219.

Nyka, M. (2019). Legal approaches to the problem of pollution of marine environment with plastic. Zeszyty Nauk. Akad. Morskiej Szczecin. 59, $162-167$.

Ogunola, O. S., Onada, O. A., and Falaye, A. E. (2018). Mitigation measures to avert the impacts of plastics and microplastics in the marine environment (a review). Environ. Sci. Pollut. Res. 25, 9293-9310. doi: 10.1007/s11356-0181499-z

Pacheco-Vega, R. (2018). Mapping A New Field of Scholarship. Available online at: http://www.raulpacheco.org/2018/01/mapping-a-new-field-of-scholarship/ (accessed March 20, 2021).

Raubenheimer, K., and McIlgorm, A. (2017). Is the Montreal Protocol a model that can help solve the global marine plastic debris problem? Mar. Policy 81, 322-329. doi: 10.1016/j.marpol.2017.04.014

Raubenheimer, K., and McIlgorm, A. (2018b). Can the basel and stockholm conventions provide a global framework to reduce the impact of marine plastic litter? Mar. Policy 96, 285-290.

Raubenheimer, K., and McIlgorm, A. (2018a). Can a global fund help solve the global marine plastic debris problem? J. Ocean Coast. Econ. 5:6. doi: 10.15351/ 2373-8456.1078
Raubenheimer, K., and Urho, N. (2020). Rethinking global governance of plasticsthe role of industry. Mar. Policy 113:103802.

Raubenheimer, K., McIlgorm, A., and Oral, N. (2018). Towards an improved international framework to govern the life cycle of plastics. Rev. Eur. Comp. Int. Environ. Law 27, 210-221. doi: 10.1111/reel.12267

Revel, M., Châtel, A., and Mouneyrac, C. (2018). Micro (nano) plastics: a threat to human health? Curr. Opin. Environ. Sci. Health 1, 17-23. doi: 10.1016/j.coesh. 2017.10.003

Ritchie, H., and Roser, M. (2018). Plastic Pollution. OurWorldInData. Available online at: https://ourworldindata.org/plastic-pollution

Rochman, C. M. (2016). Strategies for reducing ocean plastic debris should be diverse and guided by science. Environ. Res. Lett. 11:041001. doi: 10.1088/17489326/11/4/041001

Rochman, C. M., Kross, S. M., Armstrong, J. B., Bogan, M. T., Darling, E. S., Green, S. J., et al. (2015). Scientific Evidence Supports A Ban On Microbeads. Washington, DC: ACS Publications.

Schröder, P., and Chillcott, V. (2019). "The politics of marine plastics pollution," in The Circular Economy and the Global South: Sustainable Lifestyles and Green Industrial Development, eds P. Schröder, M. Anantharaman, K. Anggraeni, and T. J. Foxon (London: Routledge).

Schuyler, Q., Hardesty, B. D., Lawson, T., Opie, K., and Wilcox, C. (2018). Economic incentives reduce plastic inputs to the ocean. Mar. Policy 96, 250255.

Simon, N., and Schulte, M. L. (2017). Stopping Global Plastic Pollution: The Case For An International Convention. Berlin: Heinrich-Böll-Stiftiftung.

Simon, N., Raubenheimer, K., Urho, N., Unger, S., Azoulay, D., Farrelly, T., et al. (2021). A binding global agreement to address the life cycle of plastics. Science 373, 43-47. doi: 10.1126/science.abi9010

Stafford, R., and Jones, P. J. S. (2019). Viewpoint - ocean plastic pollution: a convenient but distracting truth? Mar. Policy 103, 187-191. doi: 10.1016/j. marpol.2019.02.003

Stoett, P., and Vince, J. (2019). "The plastic-climate nexus: linking science, policy, and justice," in Climate Change and Ocean Governance: Politics and Policy for Threatened Seas, ed. P. G. Harris (Cambridge: Cambridge University Press). doi: 10.1128/mSystems.00471-21

Stoll, T., Stoett, P., Vince, J., and Hardesty, B. D. (2020). "Governance and measures for the prevention of marine debris," in Handbook of Microplastics in the Environment, eds T. Rocha-Santos, M. Costa, and C. Mouneyrac (Cham: Springer International Publishing), 1-23. doi: 10.1016/j.wasman.2017. 09.003

Ten Brink, P., Schweitzer, J.-P., Watkins, E., Janssens, C., De Smet, M., Leslie, H., et al. (2018). Circular economy measures to keep plastics and their value in the economy, avoid waste and reduce marine litter. Economics 3, 1-14. doi: 10.1007/978-981-15-7525-9_60-1

Tessnow-von Wysocki, I., and Le Billon, P. (2019). Plastics at sea: treaty design for a global solution to marine plastic pollution. Environ. Sci. Policy 100, 94-104. doi: 10.1016/j.envsci.2019.06.005

Thompson, R. C. (2015). "Microplastics in the marine environment: sources, consequences and solutions," in Marine Anthropogenic Litter, eds L. Gutow, M. Bergmann, and M. Klages (Cham: Springer), $185-200$.

Thushari, G., and Senevirathna, J. (2020). Plastic pollution in the marine environment. Heliyon 6, e04709. doi: 10.1016/j.heliyon.2020. e04709

Tiller, R., and Nyman, E. (2018). Ocean plastics and the BBNJ treaty-is plastic frightening enough to insert itself into the BBNJ treaty, or do we need to wait for a treaty of its own? J. Environ. Stud. Sci. 8, 411-415. doi: 10.1007/s13412018-0495-4

Tiller, R., Arenas, F., Galdies, C., Leitão, F., Malej, A., Romera, B. M., et al. (2019). Who cares about ocean acidification in the plasticene? Ocean Coast. Manag. 174, 170-180. doi: 10.1016/j.ocecoaman.2019.03.020

UNCLOS (1982). United Nations Convention on The Law of The Sea of 10 December 1982. Montego Bay: UNCLOS.

UNEP (2021). 154th Meeting of the Committee of Permanent RepresentativesChair's summary. Nairobi: UNEP.

van der Maesen, L. J. (2018). Addressing marine plastic pollution: the plastic soup foundation and the four-dimensional application of the social quality approach. Int. J. Soc. Qual. 8, 47-77. 
Vegter, A. C., Barletta, M., Beck, C., Borrero, J., Burton, H., Campbell, M. L., et al. (2014). Global research priorities to mitigate plastic pollution impacts on marine wildlife. Endanger. Species Res. 25, 225-247. doi: 10.3354/esr00623

Villarrubia-Gómez, P., Cornell, S. E., and Fabres, J. (2018). Marine plastic pollution as a planetary boundary threat - the drifting piece in the sustainability puzzle. Mar. Policy 96, 213-220.

Vince, J., and Hardesty, B. D. (2017). Plastic pollution challenges in marine and coastal environments: from local to global governance. Restor. Ecol. 25, 123-128. doi: 10.1111/rec. 12388

Vince, J., and Hardesty, B. D. (2018). Governance solutions to the tragedy of the commons that marine plastics have become. Front. Mar. Sci. 5:214. doi: $10.3389 /$ fmars.2018.00214

Vince, J., and Stoett, P. (2018). From problem to crisis to interdisciplinary solutions: plastic marine debris. Mar. Policy 96, 200-203. doi: 10.1016/j.marpol. 2018.05.006

Worm, B., Lotze, H. K., Jubinville, I., Wilcox, C., and Jambeck, J. (2017). Plastic as a persistent marine pollutant. Annu. Rev. Environ. Resour. 42, 1-26. doi: 10.1146/annurev-environ-102016-060700

$\mathrm{Wu}, \mathrm{H} . \mathrm{H}$. (2020). A study on transnational regulatory governance for marine plastic debris: trends, challenges, and prospect. Mar. Policy (in press). doi: 10.1016/j.marpol.2020.103988

WWF (2021). Success Criteria for a New Treaty on Plastic Pollution. WWF. Available online at: https://www.wwf.no/assets/attachments/SUCCESSCRITERIA-for-a-new- treaty-on-plastic-pollution-FINAL-DRAFT-30-AUG2021-WEB-medium-res.pdf
WWF, The Ellen MacArthur Foundation, and BCG (2020). The Business Case for a UN Treaty on Plastic Pollution. WWF. Available online at: https://www. plasticpollutiontreaty.org/UN_treaty_plastic_poll_report.pdf

Xanthos, D., and Walker, T. R. (2017). International policies to reduce plastic marine pollution from single-use plastics (plastic bags and microbeads): a review. Mar. Pollut. Bull. 118, 17-26. doi: 10.1016/j.marpolbul.2017. 02.048

Conflict of Interest: The authors declare that the research was conducted in the absence of any commercial or financial relationships that could be construed as a potential conflict of interest.

Publisher's Note: All claims expressed in this article are solely those of the authors and do not necessarily represent those of their affiliated organizations, or those of the publisher, the editors and the reviewers. Any product that may be evaluated in this article, or claim that may be made by its manufacturer, is not guaranteed or endorsed by the publisher.

Copyright (c) 2021 Cowan and Tiller. This is an open-access article distributed under the terms of the Creative Commons Attribution License (CC BY). The use, distribution or reproduction in other forums is permitted, provided the original author(s) and the copyright owner(s) are credited and that the original publication in this journal is cited, in accordance with accepted academic practice. No use, distribution or reproduction is permitted which does not comply with these terms. 